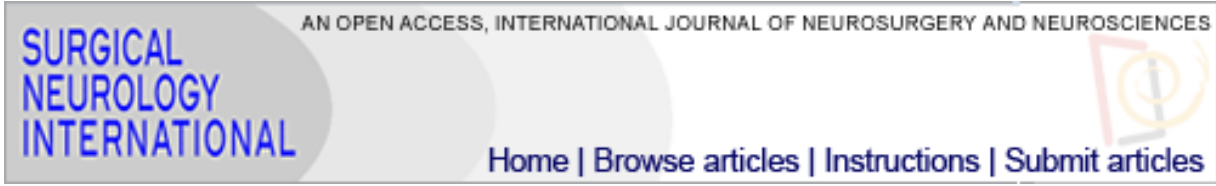

Surg Neurol Int. 2016; 7: 31.

PMCID: PMC4828955

Published online 2016 Mar 30. doi: 10.4103/2152-7806.179429

\title{
A rare case of solitary brain Langerhans cell histiocytosis with intratumoral hemorrhage in a patient affected by Turner syndrome
}

\author{
Francesca Granata, Rosa Morabito, Giovanni Grasso, ${ }^{1}$ Elisabetta Alafaci, ${ }^{2}$ Francesco M. Salpietro, ${ }^{3}$ and Concetta \\ Alafaci $^{3, *}$ \\ Department of Radiological Sciences, University of Messina, Messina, Italy \\ ${ }_{1}^{1}$ Department of Experimental Biomedicine and Clinical Neurosciences (BIONEC), University of Palermo, Palermo, Italy \\ ${ }^{2}$ Department of Human Pathology, Medical Oncology Unit, University of Messina, Messina, Italy \\ 3 Department of Neurosurgery, University of Messina, Messina, Italy \\ Francesca Granata: fgranata@unime.it; Rosa Morabito: rosa.morabito85@ \\ Alafaci: ealafaci@unime.it; Francesco M. Salpietro: fsalp@@unime.it; Concetta Alafaci: calafaci@unime.it \\ * Corresponding author
}

Received 2016 Feb 3; Accepted 2016 Feb 29.

Copyright : ‘ 2016 Surgical Neurology International

This is an open access article distributed under the terms of the Creative Commons Attribution-NonCommercial-ShareAlike 3.0 License, which allows others to remix, tweak, and build upon the work non-commercially, as long as the author is credited and the new creations are licensed under the identical terms.

\section{Abstract}

\section{Background:}

Langerhans cell histiocytosis $(\mathrm{LCH})$ is a rare disease involving clonal proliferation of cells with characteristics similar to bone marrow-derived Langerhans cells. The case of a young woman, affected by Turner syndrome and a solitary intraparenchymal LCH associated with an osteolytic lesion of the overlying skull, is presented.

\section{Case Description:}

The patient, with an insidious history of headache and a growing soft mass in the left frontal region, presented with a sudden generalized tonic-clonic epileptic seizure. Neuroradiological investigations showed an osteolytic lesion of the left frontal bone and an underlying brain lesion associated with recent signs of bleeding. The patient was operated on with a complete removal of the lesion. The postoperative course was uneventful.

\section{Conclusions:}

The clinical, neuroradiological, and intraoperative findings are presented, along with a review of the literature. Although rare, LCH should be considered in the differential diagnosis when a scalp lesion occurs with a progressive growing.

Keywords: Hemorrhage, Langerhans cell histiocytosis, skull neoplasm

\section{INTRODUCTION}


Histiocytic disorders are a group of diseases derived from macrophages and dendritic cells resulting in a wide range of clinical conditions.[20] The World Health Organization, according to the type of histiocyte involved, classifies this pathology into dendritic cell disorders, macrophage-related disorders, and malignant histiocytic disorders.[15,20] Langerhans cell histiocytosis $(\mathrm{LCH})$ is the most common dendritic cell disorder.[20]

We describe the case of a young female, affected by Turner syndrome (TS), with a solitary brain LCH associated with an osteolytic lesion of the overlaying skull extending to the surrounding subgaleal soft tissues.

\section{CASE REPORT}

\section{Clinical presentation}

A 30-year-old woman affected by TS, suffering from headache, vomiting, and increase in body temperature was admitted. Her past medical history was characterized by myoclonic seizures, pharmacologically treated, since she was 8-year-old. Four months before the admission, she noticed a progressive growing nodular lesion in the left frontal side of the skull, which was painful on palpation. An ultrasound examination revealed an extracranial isoechoic mass diagnosed as a dermoid cyst.

At admission, the patient developed a generalized tonic-clonic epileptic seizure. She underwent a computed tomography (CT) examination which showed an osteolytic lesion, $33 \mathrm{~mm}$ in diameter, of the left frontal bone extending to the surrounding subgaleal soft tissues. The lytic lesion had the "punched-out" appearance, caused by the asymmetric destruction of the bone. There was no evidence of periosteal reaction or bone sclerosis. CT scan also demonstrated an irregular parenchymal left frontal mass, below the bone defect. The tumor had an inhomogeneous density, with some hyperdense components, expressing a recent intratumoral bleeding. Thoraco-abdominal CT scan did not demonstrate abnormal findings in other organs, including lungs, pancreas, and spleen.

Magnetic resonance (MR) examination was performed. The lesion showed strong and irregular increased signal intensity on T1-weighted images and mixed low-high intensity on T2-weighted images. The presence of low- and high-signal components suggested different phases of intratumoral hemorrhage. After gadolinium administration, a slight peripheral enhancement of the lesion was demonstrated.

\section{Treatment}

The patient underwent surgical treatment. Following the left frontal skin incision, the bone defect was detected. A surrounding craniotomy was performed. The dura appeared regular without macroscopic signs of tumor infiltration. The lesion, which macroscopically appeared soft and reddish blue with bleeding signs, was completely removed. A cranioplasty, by using methyl methacrylate, was performed to reconstruct the bone defect. The postoperative course was uneventful. Postoperative MR imaging revealed no residual tumor.

Figure 1 shows the neuroradiological examinations performed before and following the surgery.

Histological examination showed a normal dura. The brain lesion showed numerous blood cells and deposits of hemosiderin. The tumor was made up of eosinophils, lymphocytes, macrophage with hemosiderin, and many histiocytes in addition to many Langerhans giant cells. The histiocytes and Langerhans cells were positive for S-100 and CD1a proteins. The histological diagnosis was LCH. 
LCH is a rare immunologic disorder involving clonal proliferation and accumulation in multiple organs of histiocyte-like cells (Langerhans cell) deriving from bone marrow and capable of migrating from skin to lymph nodes. $[\underline{1}, \underline{16}, \underline{20}]$

LCH has an estimated incidence of 3-5 pediatric cases per million/year and 1-2 adult cases per million/year.[19] LCH is named because of its similarity to the Langerhans cells which are normally found in the skin and mucosa. Cells of LCH derive from myeloid dendritic cells that lack the ability to be a functional antigen-presenting cell.[2] They exhibit the same antigens, CD1a, S-100, and CD 207, and the same intracytoplasmic X-shaped organelles, the Birbeck granules, as found in Langerhans cells.[17,20]

The disease is confined in one organ in about $55 \%$ of the cases whereas in the remaining cases, it presents as a multisystem disease.[19] According to the International Classification of Disease-Oncology, LCH is classified into three groups on the basis of the number of lesions and organs involved.[15,19] The unifocal $\mathrm{LCH}$, formerly known as eosinophilic granuloma, is the most common form being observed in approximately $70 \%$ of the cases. It usually affects young patients, limited to a single bone or few bones, and it may involve the lung.[15,20] Rarely, it can involve the digestive system, salivary glands, and thymus. An unifocal brain localization is very rare.[르, 14$]$

The multifocal unisystem is approximately $20 \%$ of LCH cases and usually involves $2-5$-year-old children. $[\underline{15}, \underline{20}]$ Such a variation may affect multiple bones and the reticulo-endothelial system (i.e. liver, spleen, lymph nodes, and skin). It is often accompanied by diabetes insipidus when the pituitary gland is involved. [6]

The multifocal multisystem is approximately the $10 \%$ of LCH. It is typically diagnosed in the first 2 years of life and it is characterized by a poor prognosis due to the involvement of the reticulo-endothelial system, anemia, thrombocytopenia, and respiratory distress.[20]

Pathogenetic mechanisms underlying the LCH is a matter of debate. One of the hypotheses is that LCH can be an immunological disorder characterized by an overexpression and/or deficient cytokine activation control of cell proliferation and differentiation into immunocompetent or hematopoietic lines.[2, 14$]$ In this regard, it has been proven that granulocyte macrophage colony-stimulating factor and tumor necrosis factor-alpha play an important role in the generation of Langerhans cells from hematopoietic stem cells.[4] Some studies suggest a possible viral etiology being the Epstein-Barr virus, human herpes virus 6 and $8[\underline{8}]$ as well as cytomegalovirus, adenoviruses, papovaviruses, and HIV infections often found.[14]

Cases of familiar LCH have rarely been described.[14]

A relationship between the diffuse form of Langerhans histiocytosis, acute lymphoblastic leukemia, and malignant lymphomas has also been reported.[14]

We have reported the case of a young patient with a solitary brain LCH with intratumoral bleeding associated with an osteolytic lesion of the skull. Intracranial LCH with intratumoral hemorrhage is a rare condition. According to the literature, only one case of a parietal LCH lesion associated with bleeding components has been reported.[18] Furthermore, there are few reports about intracranial LCH presenting as an epidural hematoma or bleeding cyst. $[\underline{5}, \underline{11}, \underline{12}, \underline{13}, \underline{18}]$ In case of intratumoral hemorrhage, the bleeding could be related to vascular occlusion or necrosis due to endothelial cells proliferation, rupture of fragile tumoral vessels, disappearance or reduction of the supportive tissue surrounding the tumoral vessels, and infiltration of vessel walls.[18]

In our case, LCH was found in the skull, with the characteristic of a well-defined lytic lesion in the brain. Since the dura layer was not infiltrated, we can provide evidence of a double LCH localization.

Furthermore, our patient was also affected by TS. TS is a congenital condition that affects $1 / 2500$ births, 
resulting from the absence or structural alteration of the second sex chromosome. It is usually associated with short stature, gonadal dysgenesis, and variable dysmorphic features.[7] Although many reports describe the association between TS and various immunological disorders,[10] to date, there is no evidence about the association of LCH and TS.

\section{CONCLUSIONS}

We report a very rare occurrence of a double LCH involving the skull and the overlaying brain, sparing the dura.

Although rare, $\mathrm{LCH}$ affecting the brain should be considered, especially when a scalp lesion with a progressive growing occurs.

\section{Financial support and sponsorship}

Nil.

\section{Conflicts of interest}

There are no conflicts of interest.

\section{Footnotes}

http://surgicalneurologyint.com/A-rare-case-of-solitary-brain-Langerhans-cell-histiocytosis-with-intratumoralhemorrhage-in-a-patient-affected-by-Turner-syndrome/

\section{REFERENCES}

1. Alexiou GA, Mpairamidis E, Sfakianos G, Prodromou N. Cranial unifocal Langerhans cell histiocytosis in children. J Pediatr Surg. 2009;44:571-4. [PubMed: 19302861]

2. Bergmann M, Yuan Y, Brück W, Palm KV, Rohkamm R. Solitary Langerhans cell histiocytosis lesion of the parieto-occipital lobe: A case report and review of the literature. Clin Neurol Neurosurg. 1997;99:50-5. [PubMed: 9107469]

3. Cai S, Zhang S, Liu X, Lin Y, Wu C, Chen Y, et al. Solitary Langerhans cell histiocytosis of frontal lobe: A case report and literature review. Chin J Cancer Res. 2014;26:211-4. [PMCID: PMC4000902]

[PubMed: 24826063]

4. Caux C, Dezutter-Dambuyant C, Schmitt D, Banchereau J. GM-CSF and TNF-alpha cooperate in the generation of dendritic Langerhans cells. Nature. 1992;360:258-61. [PubMed: 1279441]

5. Cho DY, Liau WR, Chiang IP. Eosinophilic granuloma with acute epidural hematoma: A case report. Pediatr Neurosurg. 2001;35:266-9. [PubMed: 11741122]

6. Ghafoori S, Mohseni S, Larijani B, Mohajeri-Tehrani MR. Pituitary stalk thickening in a case of langerhans cell histiocytosis. Arch Iran Med. 2015;18:193-5. [PubMed: 25773695]

7. Haltrich I, Pikó H, Pamjav H, Somogyi A, Völgyi A, David D, et al. Complex X chromosome rearrangement associated with multiorgan autoimmunity. Mol Cytogenet. 2015;8:51.

[PMCID: PMC4506572] [PubMed: 26191082]

8. Hoover KB, Rosenthal DI, Mankin H. Langerhans cell histiocytosis. Skeletal Radiol. 2007;36:95-104. [PubMed: 17028900]

9. Lajolo C, Campisi G, Deli G, Littarru C, Guiglia R, Giuliani M. Langerhans's cell histiocytosis in old 
subjects: Two rare case reports and review of the literature. Gerodontology. 2012;29:e1207-14.

[PubMed: 22612839]

10. Larizza D, Calcaterra V, Martinetti M. Autoimmune stigmata in Turner syndrome: When lacks an $X$ chromosome. J Autoimmun. 2009;33:25-30. [PubMed: 19349146]

11. Lee BD, Lee W, Lee J, Son HJ. Eosinophilic granuloma in the anterior mandible mimicking radicular cyst. Imaging Sci Dent. 2013;43:117-22. [PMCID: PMC3691372] [PubMed: 23807936]

12. Lee BH, George S, Kutok JL. Langerhans cell histiocytosis involving the thymus. A case report and review of the literature. Arch Pathol Lab Med. 2003;127:e294-7. [PubMed: 12823060]

13. Martínez-Lage JF, Bermúdez M, Martínez-Barba E, Fuster JL, Poza M. Epidural hematoma from a cranial eosinophilic granuloma. Childs Nerv Syst. 2002;18:74-6. [PubMed: 11935249]

14. Moscinski LC, Kleinschmidt-DeMasters BK. Primary eosinophilic granuloma of frontal lobe.

Diagnostic use of S-100 protein. Cancer. 1985;56:284-8. [PubMed: 3891065]

15. Mosiewicz A, Rola R, Jarosz B, Trojanowska A, Trojanowski T. Langerhans cell histiocytosis of the parietal bone with epidural and extracranial expansion - Case report and a review of the literature. Neurol Neurochir Pol. 2010;44:196-203. [PubMed: 20496290]

16. Nicollas R, Rome A, Belaïch H, Roman S, Volk M, Gentet JC, et al. Head and neck manifestation and prognosis of Langerhans' cell histiocytosis in children. Int J Pediatr Otorhinolaryngol. 2010;74:669-73. [PubMed: 20363036]

17. Saliba I, Sidani K, El Fata F, Arcand P, Quintal MC, Abela A. Langerhans' cell histiocytosis of the temporal bone in children. Int J Pediatr Otorhinolaryngol. 2008;72:775-86. [PubMed: 18355926]

18. Uranishi R, Nikaido Y, Eguchi T, Bessho H, Fujimoto T, Inui T. Eosinophilic granuloma associated with intratumoral hemorrhage - Case report. Neurol Med Chir (Tokyo) 1996;36:458-61.

[PubMed: 8741377]

19. Watanabe S, Yamamoto T, Satomi K, Matsuda M, Akutsu H, Ishikawa E, et al. Comparison of magnetic resonance imaging with invasive histological findings of Langerhans cell histiocytosis. Brain Tumor Pathol. 2014;31:182-6. [PubMed: 24604297]

20. Zaveri J, La Q, Yarmish G, Neuman J. More than just Langerhans cell histiocytosis: A radiologic review of histiocytic disorders. Radiographics. 2014;34:2008-24. [PubMed: 25384298]

\section{Figures and Tables}

Figure 1 

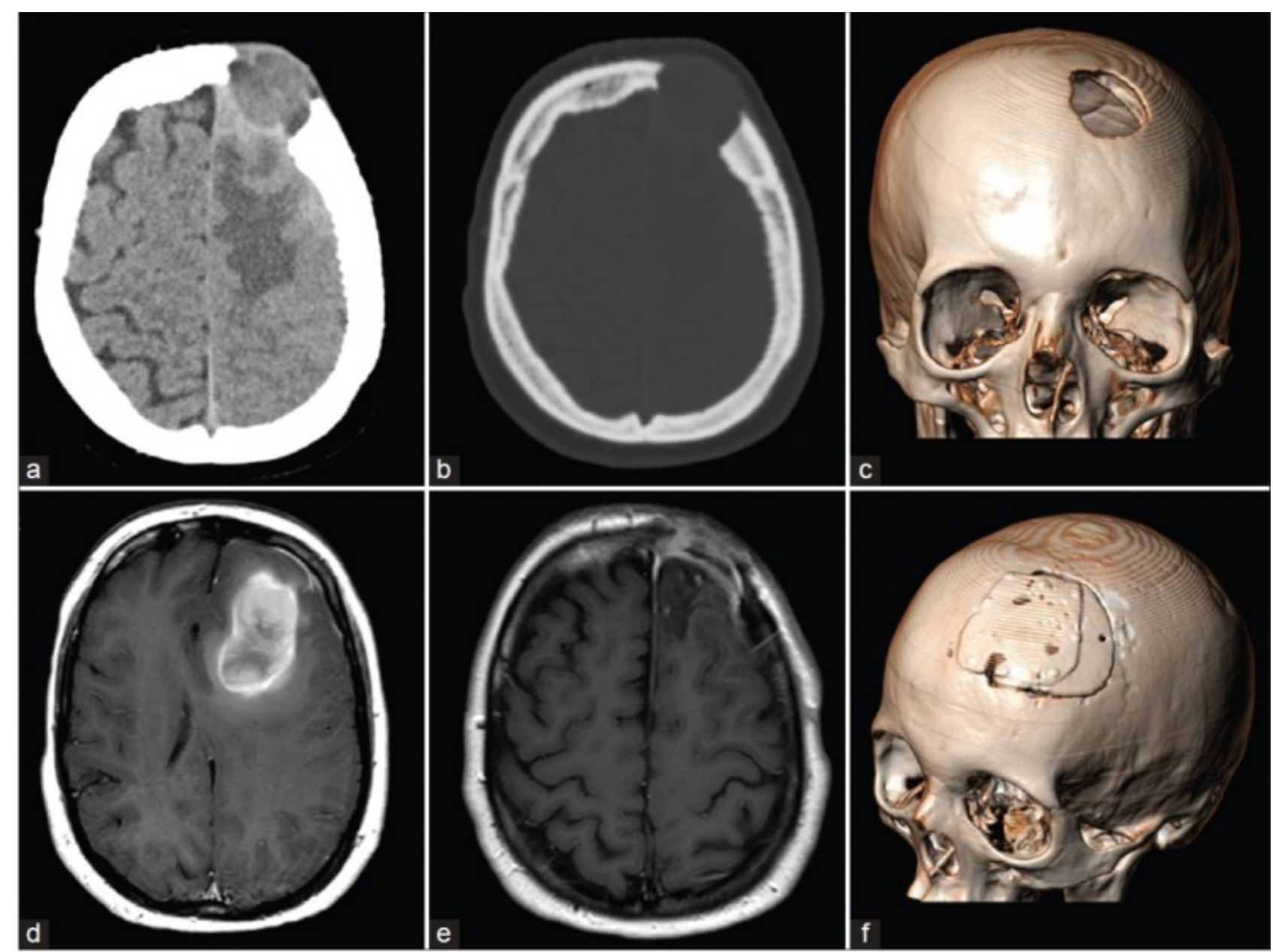

( $a$ and b) Computed tomography scan showing an osteolytic lesion of the left frontal bone, extending to the surrounding subgaleal soft tissues. An irregular left frontal lobe mass, below the bone defect, was also present. (c) Three-dimensional computed tomography scan showing the frontal bone defect. (d) Magnetic resonance examination showing the lesion with an irregular increased signal intensity on T1-weighted images and the coexistence of low- and high-signal components, suggesting different phases of intratumoral hemorrhage. After gadolinium administration, a slight peripheral enhancement was evident. (e) Postoperative magnetic resonance imaging revealing the contrast enhancement of the dural layer with no residual tumor. (f) Three-dimensional computed tomography scan showing the reconstruction of the bone defect

\section{Articles from Surgical Neurology International are provided here courtesy of Medknow Publications}

